\title{
Evaluation of two communication strategies to improve udder health management
}

\author{
J. Jansen, ${ }^{* 1}$ R. J. Renes, ${ }^{*}$ and T. J. G. M. Lam† \\ *Department of Communication Science, Wageningen University, PO Box 8130, 6700 EW Wageningen, the Netherlands \\ †Dutch Udder Health Centre UGCN at GD Animal Health Service Ltd., PO Box 2030, 7420 AA Deventer, the Netherlands
}

\begin{abstract}
Worldwide, programs to improve udder health are implemented using communication tools and methods that inform and persuade dairy farmers. This study evaluated 2 communication strategies used in a mastitis control program in the Netherlands. To improve farmers' udder health management, tools such as instruction cards, treatment plans, checklists and software were developed following an argument-based comprehensive "central route." These tools were used during on-farm study group meetings for farmers organized by veterinarians and also during individual veterinarian-farmer interactions. The second strategy aimed at adopting a single management practice to increase the use of milking gloves during milking. This approach followed a straightforward "peripheral" route that used implicit persuasion techniques. Results of an online survey of 374 Dutch dairy farmers showed that most farmers were able and willing to use the educational management tools to increase udder health on their farms. They evaluated the tools positively regardless of the mastitis problems on their farms. This seems to indicate that the central route of communication is most effective when farmers are motivated to work on udder health in general. Results of repeated random telephone surveys before, during, and after the campaign on the use of milking gloves showed that the use of gloves increased from 20.9 to $42.0 \%$ of the respondents. Respondents' opinions about milking gloves also changed favorably, indicating that a relatively short peripheral campaign on a single action can have a sustained effect on farmers' behavior. Both communication strategies seem to be potentially successful in disseminating knowledge to a specific target group of farmers and in changing that group's behavior. However, to reach as many farmers as possible, the strategies should be combined. When optimizing these strategies, both the farmers' motivation to work on udder health and the aim of the campaign should be considered. When aiming to improve general
\end{abstract}

Received June 30, 2009

Accepted October 5, 2009.

${ }^{1}$ Corresponding author: jolanda.jansen@wur.nl udder health management, the central route seems to be effective if farmers are already motivated to optimize their udder health management. For farmers who are less motivated to work on udder health, the peripheral route seems to be most effective when aiming to change a single management practice. The evaluated communication strategies are examples of how management practices to control mastitis can be effectively communicated to farmers. As such, this study contributes to optimizing future programs to control and prevent diseases.

Key words: communication, mastitis, education, extension

\section{INTRODUCTION}

Mastitis is one of the main health issues in dairy production and remains a major challenge for the global dairy industry (Bradley, 2002; LeBlanc et al., 2006). Worldwide, programs to control mastitis are implemented using both well-known and newly developed communication tools and methods to inform and persuade farmers. In these udder health programs, much effort is put into developing education materials and informative tools such as udder health quick scans, illustrated fact sheets, and treatment protocols. In addition, specific management practices, such as wearing milking gloves during milking, are recommended. Scientists and veterinarians are constantly debating how to improve both the scientific content of educational tools and the effectiveness of recommended management practices, such as the best milking procedures or treatment plans. Although practical udder health tools, research outcomes, and best practices should be technically optimal, they also have to be used by farmers to be effective. Thus, it is important to communicate these issues and tools effectively to improve farm management. Evaluation of extension education programs is necessary to optimize future campaigns that seek to control and prevent diseases by changing farmers' management practices (Chase et al., 2006).

According to fundamental social psychological theories, 2 communication strategies can be distinguished 
when the adoption of behavior; for example, udder health management practices, is desired: (1) a comprehensive traditional "central" route, which assumes that people make rational decisions based on scientifically proven information and argumentation, and (2) a more indirect and unconscious "peripheral" route that includes cues or heuristics that automatically and subconsciously persuade farmers to change their behavior without using rational argumentation or reasoning (Petty and Cacioppo, 1986; Petty and Wegener, 1999; Bargh and Morsella, 2008). Most current interventions aiming at changing people's behavior on udder health follow the central route. However, this route may have limited effect (Leeuwis, 2004; Webb and Sheeran, 2006) because rational decision-making to change behavior requires a basic motivation to think rationally and to elaborate on provided arguments (Petty and Cacioppo, 1986). According to this theory, farmers need to be motivated to work on udder health so that they are willing to process and implement information such as education materials and informative, science-based udder health tools. However, if farmers are not motivated, they may still be persuaded to change their behavior by the peripheral route. Cialdini (2001) shows that cues such as authority or expertise (e.g., "if my veterinarian says so, it must be right") or cues of social proof (e.g., "if all farmers are doing it, then it must be good") are able to influence people without them being aware of it.

To date, no research has been done on how central and peripheral communication strategies can be used to improve udder health, what their potential efficacies are, and to what extent motivation is required when the traditional central route of communication is used. This paper aims to explore these issues by the separate evaluation of 2 implemented communication strategies used in a specific program to improve udder health management in the Netherlands.

\section{MATERIALS AND METHODS}

\section{The Udder Health Program}

In 2005, a project was begun to improve udder health in the Netherlands: the 5-year mastitis control program of the Dutch Udder Health Centre (UGCN). The program consists of both central and peripheral communication strategies to change farmers' behavior (Lam et al., 2007). For the central strategy, on-farm study groups and comprehensive education materials were developed for farmers who were interested in participating in programs to improve udder health management. This strategy focused on the broader goal of improving udder health by educating farmers using comprehen- sive science-based and rational argumentation about mastitis prevention and treatment. In 2008, almost 200 veterinary practices participated in the program. Through these veterinary practices, more than 17,000 dairy farmers (approximately $78 \%$ of all Dutch dairy farmers) were informed about the udder health project, of which 3,169 farmers (18\%) participated in the onfarm study groups organized by their veterinarian.

For the peripheral route, a straightforward massmedia campaign was developed that focused on a single aspect of mastitis prevention: the use of milking gloves during milking. The campaign was developed by UGCN in cooperation with 2 main agricultural suppliers, a research institute (Animal Sciences Group at Wageningen University), and the Dutch Federation of Agricultural and Horticultural Organizations (LTO). In this campaign the argumentation for why milking gloves contribute to udder health was very limited; mostly implicit persuasion techniques, such as distribution of free samples, were used to persuade farmers to wear gloves during milking,

\section{The Central Route: Distribution of Informative and Educational Tools}

For the central route, 14 tools were evaluated (see Table 1). Most of the 14 evaluated tools were discussed during the on-farm udder health study groups and focused on 5 themes: infectious pressure (udder health assessment questionnaire), planning and goal setting (mastitis cost calculator, udder health objectives flyer), treatment (clinical mastitis treatment protocol, treatment evaluation, illustrated fact sheets on California Mastitis Test, milk sampling technique, and injection technique), resistance (resistance assessment questionnaires), and milking and milking technique (self-evaluation test, illustrated fact sheets on milking procedures and teat condition assessment). Additionally, a practical guide to first-rate udder health was developed (Hulsen and Lam, 2008). Some tools were also discussed on an individual basis with the veterinarian and some were distributed through the UGCN Web site (http://www. ugcn.nl; see Table 1). The overall goal of these educational tools and the on-farm study group meetings was to improve udder health on these farms by changing the knowledge, attitude, and behavior of farmers.

To evaluate the central route, a quantitative online questionnaire was distributed among dairy farmers who were associated with a veterinary practice that participated in the udder health project. Therefore, all participants had access to knowledge about the program and the tools evaluated. The online questionnaire was developed by mastitis experts and communication researchers. The outcomes of 8 workshops with farmers 
Table 1. Percentage of Dutch dairy farmers, either participating or not participating in udder health study groups, being familiar with the evaluated educational tools

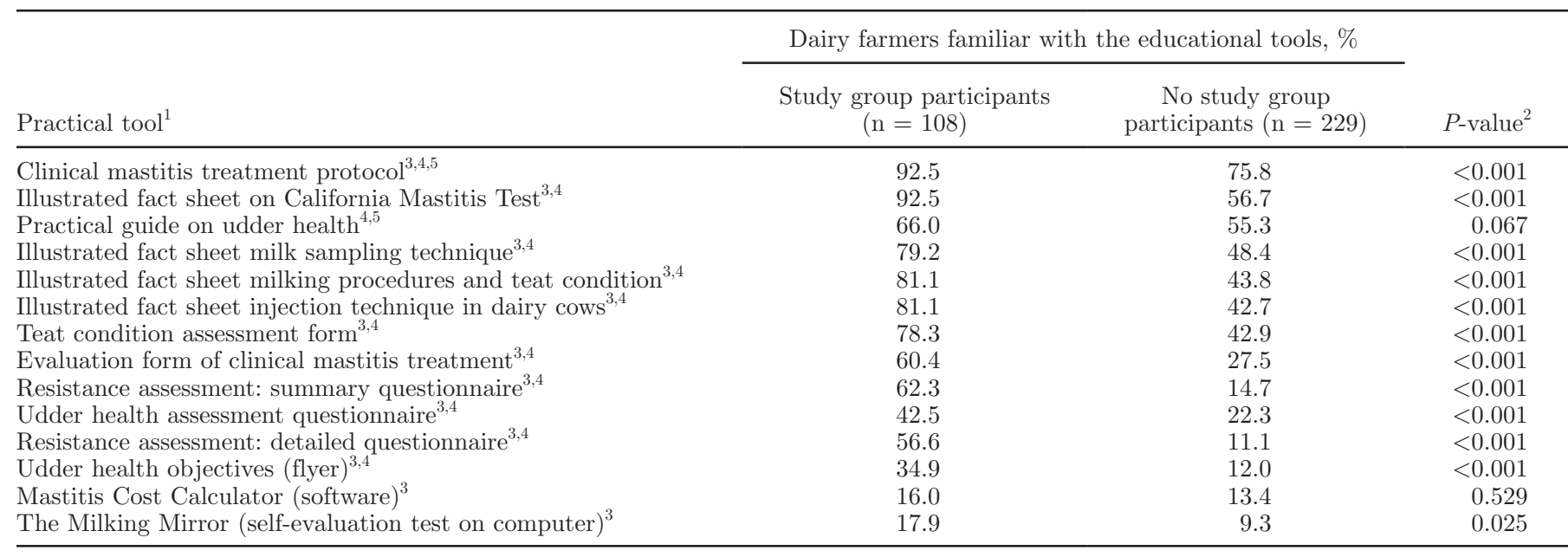

${ }^{1}$ Sorted on average familiarity with the tools among all respondents.

${ }^{2} P$-value based on Pearson chi-square between study group and no study group participants.

${ }^{3}$ Available on the udder health project Web site (http://www.ugcn.nl).

${ }^{4}$ Distributed to participating veterinary practices as study group material and for individual on-farm consultancy.

${ }^{5}$ Distributed directly to all Dutch dairy farmers.

and veterinarians also provided input for the survey. The online survey contained questions about (1) general demographic information about farm and farmer; (2) self-reported geometric bulk milk somatic cell count (BMSCC); (3) self-reported incidence of clinical mastitis, defined as abnormal milk, udder, or both; (4) motivations and attitudes toward udder health; (5) relationship with the veterinarian; and (6) evaluation of and experience with each of the 14 practical tools. To evaluate the tools, the farmers were given a picture and a clear description of each and asked if they were familiar with the tool ("do you know this tool?") and if they were interested in using it ("do you think this tool is interesting to use?"). Motivation and attitude, as well as the relationship with the veterinarian, were scored using statements (e.g., "it's important to improve udder health on my farm") and by asking for the farmer's level of agreement on a 5-point Likert scale (Likert, 1932).

A random selection of 2,913 out of 17,210 farmers associated with the involved veterinary practices were sent the internet address of the survey by e-mail (if their e-mail address was known) or by standard mail in October 2007. After $3 \mathrm{wk}$ and one reminder, 467 farmers completed the survey; $72 \%$ responded by e-mail and $28 \%$ by standard mail. To include only professional dairy farmers, 93 respondents were excluded from the analysis because they were younger than 18 , had fewer than 10 dairy cows, or produced milk only for their own household's consumption. This resulted in a final data set of 374 dairy farmers.
Descriptive analyses were used to explore farmers' familiarity with the tools and their reasons for appreciating the tools. Pearson chi-square was used to test the difference in familiarity with practical tools between study group and non-study-group participants. Twotailed Spearman correlation analyses were performed to explore the relationships between farmers' motivation, their attitudes, their relationship with the veterinarian or mastitis problems, and their interest in using the tools. The farmers' interest in the general use of the tools was quantified by the number of individual evaluated tools that a farmer was interested in. Data were analyzed with SPSS 15.0 (SPSS Inc., 2007).

\section{The Peripheral Route: Mass Media Campaign on Milking Gloves}

For the peripheral route, a campaign to increase the use of milking gloves during milking was evaluated. This campaign aimed at changing farmers' behavior through peripheral cues such as distribution of free samples and humorous postcards. The campaign consisted of 4 main strategies: (1) launch of the campaign and a Web site during a national agricultural fair; (2) humorous postcards (2) sent to farmers during the campaign to remind them to wear gloves; (3) visits to approximately $75 \%$ of the Dutch dairy farms by agricultural suppliers offering free samples of milking gloves; and (4) a $25 \%$ discount on gloves ordered from the campaign Web site. The campaign ran from November 2007 until April 2008. 
To evaluate the peripheral route, a telephone survey was conducted among randomly selected Dutch dairy farmers at 3 different moments in the course of the campaign: pre-test before the start of the campaign in November $2007\left(\mathbf{t}_{\mathbf{0}}, \mathrm{n}=287\right)$, immediately after the campaign in April $2008\left(\mathbf{t}_{1}, \mathrm{n}=300\right)$, and finally, at 1 yr after the start in December $2008\left(\mathbf{t}_{2}, \mathrm{n}=327\right)$. Farmers were asked open-ended questions about the use of milking gloves, their opinion on milking gloves, and their perceptions on the advantages of milking gloves. The interviewer scored the answers under the given categories.

Before analysis of the data, all answer categories were recoded into dummy variables and treated as individual variables with mean scores ranging from 0 (no) to 1 (yes). Descriptive analyses were used to explore the data. One-way ANOVA analyses were performed using Bonferroni contrast post-hoc tests to test whether farmers' mean scores at $t_{0}, t_{1}$, and $t_{2}$ differed significantly. These mean scores were converted into percentages when displayed in the results table. Missing data were excluded from these analyses. Although the assumption of homogeneity of variance was broken for most variables, the robust tests of equality of means using Welch and Brown-Forsythe statistics did not show deviant $P$-values. Therefore, ANOVA $F$-statistics are reported. Data were analyzed with SPSS 15.0 (SPSS Inc., 2007).

\section{RESULTS}

\section{Potential Effectiveness of the Central Route: Evaluation of Practical Tools}

The results of the survey showed that most dairy farmers (91\%) were familiar with the udder health project, mainly through farm magazines $(68 \%)$ or their veterinarian $(61 \%)$. The average respondent was 43 years old and owned 72 dairy cows producing $8,570 \mathrm{~kg}$ of milk/cow per year. Of the respondents, $32 \%$ participated in the udder health study groups. The average self-reported geometric mean BMSCC was 193,300 cells/mL with 24.1 clinical mastitis cases per 100 cows per year. The respondents differed from the 2007 Dutch average, which was 66 dairy cows producing $7,879 \mathrm{~kg}$ of milk/cow per year and a geometric mean BMSCC of 220,000 cells $/ \mathrm{mL}$. The results did not show a significant difference in self-reported udder health status between respondents who did or did not participate in the study groups. On average, the farmers in this survey were satisfied with a BMSCC of 176,280 cells $/ \mathrm{mL}$ and an annual clinical mastitis incidence of 13.5 cases per 100 cows. On average, they perceived udder health as a problem at a BMSCC of 266,200 cells $/ \mathrm{mL}$ or at an annual clinical mastitis incidence of 27.9 cases per 100 cows.
Regarding farmers' attitudes, only $3 \%$ of the respondents agreed that it was not important to improve udder health, and 95\% acknowledged the financial benefits of a decrease in mastitis. However, only a few farmers thought that they could easily reduce the number of clinical mastitis cases (10\%) or the BMSCC level (19\%). Most respondents (73\%) liked being informed about the latest developments in udder health management. A small group of farmers (13\%) stated that they had more important things on their minds than mastitis.

Table 1 shows the familiarity of farmers with the evaluated practical tools and the way they were distributed to the farmers. Study group participants were, in general, more familiar with the tools than farmers who did not participate in study groups. The results also show that farmers were more familiar with illustrated fact sheets than with questionnaires and software. The materials distributed to all farmers by mail were better known than the materials distributed only through the Web site. The results showed that although most materials were available at the veterinary practice or on the Web site, not all farmers were aware of these tools.

Regardless of how familiar the farmers were with the tools, they were asked about their potential interest in using the tools, based on a picture and description of the tool. The farmers were, on average, interested in 6.4 of the 14 tools. Study group participants were interested in more tools (7.8) than farmers who did not participate in study groups $(5.7 ; P<0.001)$. As Table 2 illustrates, farmers seemed to be interested in using most tools, with the exception of setting udder health objectives on a pre-designed form (flyer) and evaluating the effect of treatment. The practical guide on udder health and the illustrated fact sheet on the California Mastitis Test were most frequently scored as interesting to use. For some tools such as the udder health assessment questionnaire and the milk mirror self-evaluation test, many farmers did not know whether they were interested in using them (see Table 2).

\section{The Importance of Farmers' Motivation when Following the Central Route}

Spearman correlation analyses were performed to explore whether farmers' motivation is an important condition for being interested in using practical tools (see Table 3). The results show a positive relation between farmers' general interest in improving udder health and the number of tools in which they were interested. Furthermore, farmers' perception about the cost-effectiveness of preventing a high BMSCC and clinical mastitis incidence is associated with the interest in using tools. Additionally, both the farmers' perceived acceptable level of BMSCC and having a goal for udder health 
Table 2. Farmers' interest in the use of practical tools $(\mathrm{n}=374)$

\begin{tabular}{lccc}
\hline & \multicolumn{2}{c}{ Dairy farmers interested in the use of the tool, \% } \\
\cline { 2 - 4 } Practical tool & Yes & No & Don't know \\
\hline Practical guide on udder health & 66.8 & 8.7 & 24.5 \\
Illustrated fact sheet on California Mastitis Test & 62.5 & 22.1 & 15.4 \\
Illustrated fact sheet milking procedures and teat condition & 49.6 & 23.5 & 26.9 \\
Illustrated fact sheet injection technique in dairy cows & 48.7 & 27.6 & 23.7 \\
Mastitis Cost Calculator (software) & 46.4 & 20.5 & 33.1 \\
The Milking Mirror (self-evaluation test on computer) & 44.7 & 13.7 & 41.6 \\
Resistance assessment: summary questionnaire & 44.5 & 15.7 & 39.8 \\
Teat condition assessment form & 43.7 & 27.2 & 29.1 \\
Udder health assessment questionnaire & 42.8 & 14.1 & 43.1 \\
Illustrated fact sheet milk sampling technique & 42.7 & 32.7 & 24.6 \\
Clinical mastitis treatment protocol & 42.3 & 20.8 & 36.9 \\
Resistance assessment: detailed questionnaire & 40.3 & 16.8 & 42.9 \\
Evaluation form of clinical mastitis treatment & 38.5 & 28.4 & 33.1 \\
Udder health objectives (flyer) & 28.9 & 28.7 & 42.4 \\
\hline
\end{tabular}

were associated with the interest in using the practical tools. The results also showed that being familiar with the Dutch udder health project, participating in the study groups, and considering the UGCN an important source of information were positively associated with interest in the practical tools.

To explore in more depth their interest in using tools, farmers were asked to provide reasons why these tools appealed or did not appeal to them. Important reasons for liking a practical tool were the awareness it created about problems and solutions $(51.7 \%)$, positive expectations that a tool would effectively help to decrease mastitis $(29.4 \%)$, and the perception that the tool was easy to use (16.8\%). Cooperation with the veterinarian when using the tool was an important reason for $10.5 \%$ of the farmers, whereas no need to cooperate with the veterinarian was important for
$9.9 \%$ of the farmers. Less important reasons to appreciate the tools were the tool's appearance $(9.3 \%)$ and the perception that it may not be time consuming $(5.1 \%)$.

The following were the main reasons why farmers found a tool unappealing: the content was already known $(36.6 \%)$, the perception that tools did not help to decrease mastitis $(28.2 \%)$, and overlap with management systems (12.6\%). Too much paperwork or administration $(8.0 \%)$, the perceived difficulty to use a certain tool $(6.3 \%)$, and the perception that a tool may be time consuming $(5.9 \%)$ were less important reasons for not appreciating the tools. The need for cooperation with the veterinarian $(0.4 \%)$ and the perception that the tool had to be used without cooperating with the veterinarian $(0.0 \%)$ were not important for not appreciating the tools.

Table 3. Survey variables with mean scores, range, SE, and median, and the Spearman correlation with the total number of educational udder health tools a farmer was interested in $(\mathrm{n}=374)$

\begin{tabular}{|c|c|c|c|c|c|}
\hline Survey variable & Mean (range) & $\mathrm{SE}$ & Median & $\mathrm{r}_{s}$ & $P$-value ${ }^{1}$ \\
\hline I have more important things on my mind than mastitis ${ }^{2}$ & $2.23(1-5)$ & 0.05 & 2 & -0.260 & $<0.001$ \\
\hline I want to be informed about the latest udder health news ${ }^{3}$ & $0.73(0-1)$ & 0.02 & 1 & 0.230 & $<0.001$ \\
\hline I know the Dutch Udder Health Centre ${ }^{3}$ & $0.91(0-1)$ & 0.02 & 1 & 0.225 & $<0.001$ \\
\hline The decrease of clinical mastitis is financially beneficial ${ }^{2}$ & $4.31(1-5)$ & 0.03 & 4 & 0.204 & $<0.001$ \\
\hline Prevention of mastitis costs more than it brings in ${ }^{2}$ & $2.15(1-5)$ & 0.06 & 2 & -0.171 & 0.001 \\
\hline I have formulated a goal for udder health ${ }^{3}$ & $0.62(0-1)$ & 0.03 & 1 & 0.170 & 0.001 \\
\hline The bulk milk SCC level (cells $/ \mathrm{mL}$ ) that I am satisfied with is: & $176,280(50,000-350,000)$ & 2,628 & 150,000 & -0.159 & 0.002 \\
\hline My veterinarian should play a more active role on my farm ${ }^{2}$ & $2.61(1-5)$ & 0.04 & 3 & 0.150 & 0.004 \\
\hline Milk production (kg/cow per year) & $8,570(5,500-11,700)$ & 50.19 & 8,500 & 0.145 & 0.005 \\
\hline
\end{tabular}

${ }^{1}$ Only statistically significant survey variables $(P<0.01)$ are shown. Loadings are Spearman's correlation coefficient $\mathrm{r}_{s}$, two-tailed, with the sum of all individual educational tools in which a farmer was interested.

${ }^{2}$ Answers ranging from disagree (1) to agree (5).

${ }^{3}$ Answer options: no (0) and yes (1). 
Table 4. The use of gloves during milking and farmers' opinion about wearing gloves during milking measured at the beginning of the campaign $\left(\mathrm{t}_{0}\right)$, immediately after the campaign $\left(\mathrm{t}_{1}\right)$, and 1 yr after the start of the campaign $\left(\mathrm{t}_{2}\right)$

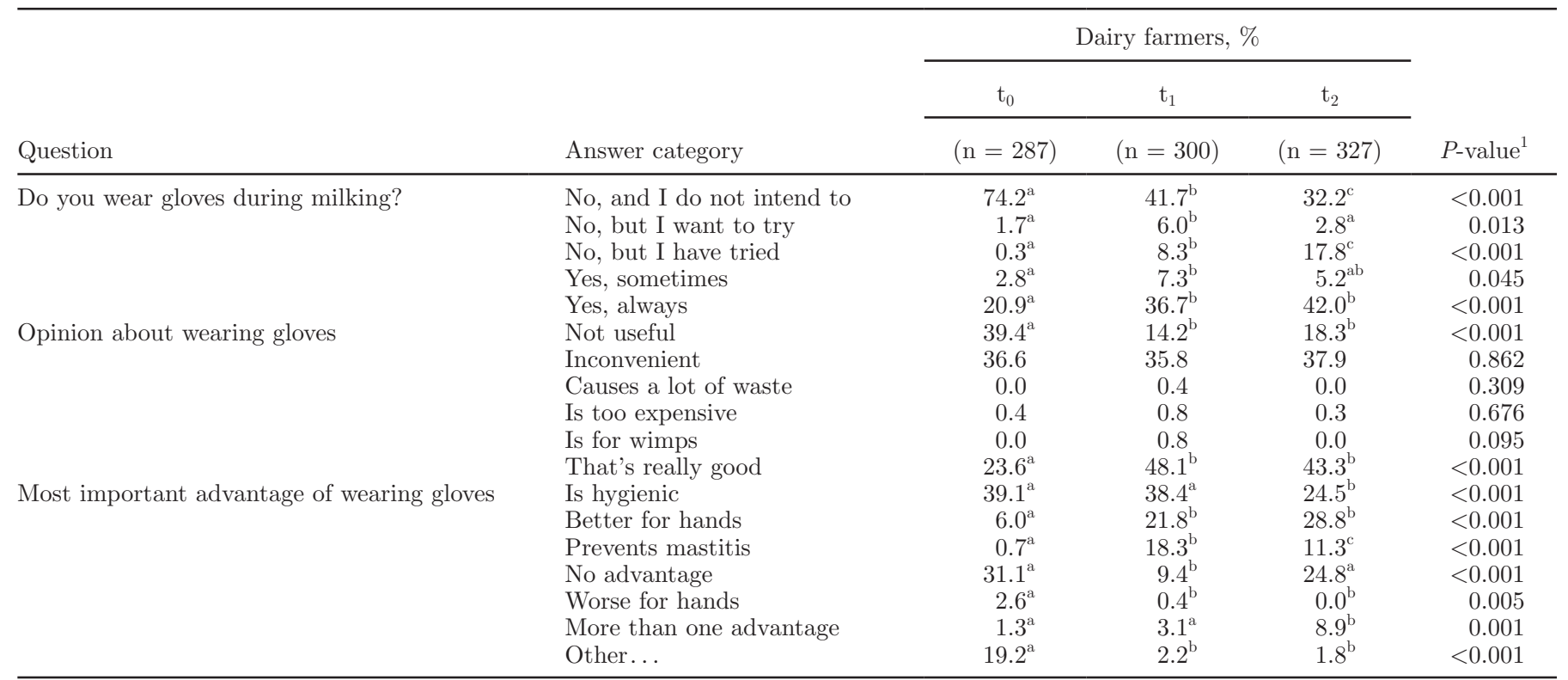

${ }^{\mathrm{a}-\mathrm{c}}$ Percentages within a row with different superscript are statistically different $(P<0.05)$.

${ }^{1} P$-values are based on one-way ANOVA analyses on mean scores at $\mathrm{t}_{0}, \mathrm{t}_{1}$, and $\mathrm{t}_{2}$, using Bonferroni post-hoc test. Before analyses, farmers' answers were recoded into dummy variables $(0=$ no and $1=$ yes $)$ and mean scores are presented in the table as percentages.

\section{Potential Effectiveness of the Peripheral Route: Evaluation of the Milking Gloves Campaign}

Table 4 shows the evaluation results of the peripheral campaign on milking gloves. The results reveal that the use of gloves increased from $20.9 \%$ at $\mathrm{t}_{0}$ to $36.7 \%$ at $\mathrm{t}_{1}$. One year after the start of the campaign $\left(\mathrm{t}_{2}\right)$, the use of gloves further increased to $42.0 \%$. The percentage of farmers never using gloves decreased from $74.1 \%$ at $\mathrm{t}_{0}$ to $41.7 \%$ at $\mathrm{t}_{1}$, and to $32.2 \%$ at $\mathrm{t}_{2}$. Additionally, the farmers' opinions of gloves changed. The percentage of farmers who thought that gloves were not useful decreased from $39.4 \%$ at $\mathrm{t}_{0}$ to $18.3 \%$ at $\mathrm{t}_{2}$. The number of farmers who thought that wearing gloves was a very good idea increased considerably $\left(23.6 \%\right.$ at $\mathrm{t}_{0}$ and $43.3 \%$ at $t_{2}$ ). The percentage of farmers who thought that wearing gloves prevented mastitis also increased $\left(0.7 \%\right.$ at $\mathrm{t}_{0}$ and $11.3 \%$ at $\left.\mathrm{t}_{2}\right)$, as did the percentage of farmers who thought that wearing gloves was better for their hands $\left(6.0 \%\right.$ at $\mathrm{t}_{0}$ and $28.8 \%$ at $\left.\mathrm{t}_{2}\right)$.

\section{DISCUSSION}

To increase our knowledge on optimization of knowledge transfer, 2 communication strategies to improve udder health management were evaluated in our study. Both strategies were potentially effective in reaching dairy farmers and changing their behavior. However, the effect of the traditional central route, which uses argument-based educational tools, is highly dependent on the farmers' intrinsic motivation to work on udder health (Petty and Cacioppo, 1986; Petty and Wegener, 1999). The results of the evaluation of the central route show that farmers' familiarity with the tools and their interest in using the tools are associated with several motivational factors, such as perceived importance of improving udder health, perceived economic benefits of udder health improvement, and the need to be informed about the latest udder health information. Thus, to maximize the effect of the central route of communication, informative and educational products have to be offered to those who are motivated to work on udder health.

To use the central communication strategy more effectively, efforts could be made to increase farmers' motivation. Two social psychological factors debated in the social psychological literature as being indispensable in motivating people to work on health promotion are a belief in a personal health threat (perceived susceptibility and perceived severity of the disease) and a belief in the effectiveness of health behavior (perceived benefits and perceived barriers of the prevention of the disease) (Rogers, 1983; Janz and Becker, 1984; Griffin et al., 1999). We assume that the mechanisms behind this model also apply to udder health promotion. For example, farmers who think that their cows are not susceptible or who think that mastitis is not a severe animal health or economic problem can be less mo- 
tivated to change mastitis management. Moreover, if required mastitis management measures are perceived as difficult or not resulting in any animal health or economic benefit or a reduced risk of receiving milk quality penalties, farmers will not be motivated to change their mastitis management (Valeeva et al., 2007; Huijps et al., 2008).

Our study supports the importance of both motivational factors. Considering the personal health threat, we found that farmers perceived very different problem and acceptance levels of BMSCC and clinical mastitis. Interestingly, no significant relationship existed between farmers' self-reported BMSCC or clinical mastitis incidence and interest in or the familiarity with the practical tools. The BMSCC level perceived as acceptable, however, did show a significant association with the interest in using tools. This indicates that the farmers' frames of reference about acceptable and problem levels of mastitis are important to consider when stimulating motivation (Leeuwis, 2004; Jansen et al., 2009).

Support for the importance of the belief in effectiveness of measures can also be found in the fact that farmers evaluated the practical tools based on their expected efficacy to improve udder health. The educational tools should create awareness of possible problems and solutions and should help to improve udder health. Our study confirms that farmers are not interested in information that they already know (Griffin et al., 1999). When using the central communication strategy with educational tools and study groups, farmers' motivation can be increased by communicating a convincing frame of reference about acceptable and problem levels of mastitis and by using arguments on the effectiveness of the recommended tools and management measures.

Even if the proposed measures to increase farmers' motivation are taken, not all farmers are willing to use all the educational tools and to rationally think about and elaborate on the arguments to improve their udder health management. Therefore, in addition to the farmers' motivation, the aim of the campaign is important when choosing a communication strategy. When the communication strategy focuses on generally achieving a complex goal (e.g., improvement of udder health on a farm) and a long-term, sustainable behavior change, the traditional central route using science-based arguments is thought to be most effective (Petty and Cacioppo, 1986; Petty and Wegener, 1999). However, this does not mean that a campaign cannot be successful if farmers are less motivated. Complex goals may not be met, but less ambitious goals; for example, aiming at changing behavior step-by-step, may be achievable (Sheeran, 2002). Single management practices (e.g., wearing milking gloves during milking) and short-term behavior change can be more easily adopted than a combination of multiple single actions to achieve a certain goal (Sheeran, 2002) and can be communicated using a peripheral route (Petty and Cacioppo, 1986; Petty and Wegener, 1999). As the results of the second study on the milking gloves campaign show, a relatively short peripheral campaign on a single management practice can be quite effective in changing behavior. The main focus of the glove campaign was to communicate that farmers have to wear gloves during milking without giving specific arguments about why to use gloves. Wearing milking gloves is associated with good udder health (Rodrigues et al., 2005) and is recommended by veterinarians and extension specialists. The campaign, however, aimed at changing the norm of not wearing gloves to one of wearing gloves "just because it's good."

The results show that not only did the use of gloves change, but the opinion of farmers about the use of gloves also changed even though no arguments were given in the campaign. It seems that farmers were convinced that wearing gloves was good because of the peripheral campaign. Based on Festinger's classic cognitive dissonance theory (Festinger, 1957), we speculate that this result is partly explained by farmer's unconscious willingness to be consistent in his or her thoughts and behavior. Many farmers started to wear gloves because of the campaign, and during the survey they were specifically asked about their attitudes toward gloves. It seems that the farmers' responses included arguments to convince themselves why they use gloves, although they may not have consciously elaborated on these arguments beforehand.

Contrary to the central route, communication using peripheral change is generally considered to be temporary, susceptible to counter-persuasion, and not able to predict future behavior (Petty and Wegener, 1999). Surprisingly, this was not the case for the milking gloves campaign. Even though there was a stronger effect on attitudes immediately after the campaign, the use of milking gloves increased more after the end of the campaign. Even with this result, the question remains as to whether the increase was an effect of the campaign itself and not an ongoing trend in Dutch dairy farming. However, a survey showed that only $16 \%$ of Dutch dairy farmers used gloves during milking in 2004 (Jansen et al., 2004), increasing by 1 to $2 \%$ a year until the start of the campaign at the end of 2007. During the campaign the use of gloves almost doubled and continued to increase after the campaign had ended even though free samples or discounts were no longer available. This shows that a substantial number of farmers continued to buy milking gloves even when extrinsic cues such as free samples were no longer present. These findings suggest internalization of the new behavior and thus a 
profound and sustainable effect of the campaign. When trying to explain the effect of the campaign, the literature shows that greater campaign effects are found in campaigns with greater reach and exposure and where there is a secular trend in society that supports the campaign (Snyder and Hamilton, 2002; Snyder et al., 2004). In our situation, the udder health program started in 2005 and their efforts to reach and motivate farmers could indeed have provided general support for this peripheral campaign. Other reasons for the success of the campaign might be the peripheral cues that were used, such as a visit from trained sales representatives who offered free samples and the power of using authorities such as UGCN, a university, and the farmers association LTO as senders of the message (Cialdini, 2001).

It can be argued that the perceived authority and expertise of the veterinarian can be an important cue to work on udder health promotion and as such stimulates farmers to follow the central as well as the peripheral route. In the Dutch program, veterinarians play an important intermediary role between the udder health project and farmers in providing the knowledge and practical tools to farmers. The veterinarian seems to be a successful intermediary because of his technical knowledge and the opportunity to approach farmers easily. However, large differences between practices exist in the way they use this type of proactive service (Lam et al., 2007; Mee, 2007). Based on the success of some participating practices and the results of this study, veterinarians clearly have ample opportunity to use practical tools in their daily communication with farmers and to distribute the tools among motivated farmers.

In general, the proposed communication strategies seem to be potentially effective in changing farmers' behavior. In this study, we did not measure the extent to which a single behavioral change affected the mastitis incidence on a farm. Mastitis is a farm-specific, complex, and multifactorial disease, and the effect of farmers' behavioral change on mastitis incidence needs to be further investigated. That said, we suggest that a combination of successive peripheral campaigns on different single management practices may be suitable for solving complex animal health issues in the long term. However, efforts need to be made to support the peripheral and central communication strategies by increasing farmers' motivation and providing effective measures for disease prevention.

\section{CONCLUSIONS}

This study shows that communication strategies to change farmers' management practices can be im- proved when both the aim of the strategy and farmers' motivational differences to work on udder health are taken into account. When aiming at complex, multifactor issues such as the general goal to improve udder health, the traditional central route using educational tools seems to be effective in reaching the motivated farmers. In addition to the central route, the peripheral route can be applied to influence farmers' behavior by including implicit persuasion techniques instead of arguments in campaigns. This route is especially effective for single management practices and when aiming at a less complicated message. To reach as many farmers as possible, both communication strategies should be used. The communication strategies described in this paper are examples of how management practices to control mastitis can be effectively communicated to farmers. As such, this study contributes to an optimization of future programs to control and prevent diseases.

\section{ACKNOWLEDGMENTS}

This study is part of the five-year mastitis program of the UGCN (Deventer, the Netherlands) and was financially supported by the Dutch Dairy Board (Zoetermeer, the Netherlands). The authors acknowledge the dairy farmers for their participation in these studies.

\section{REFERENCES}

Bargh, J. A., and E. Morsella. 2008. The unconscious mind. Perspect. Psychol. Sci. 3:73-79.

Bradley, A. J. 2002. Bovine mastitis: An evolving disease. Vet. J. 164:116-128.

Chase, L. E., O. L. Ely, and M. F. Hutjens. 2006. Major advances in extension education programs in dairy production. J. Dairy Sci. 89:1147-1154.

Cialdini, R. B. 2001. Influence: Science and Practice. 4th ed. Allyn and Bacon, Needham Heights, MA.

Festinger, L. 1957. A Theory of Cognitive Dissonance. Stanford University Press, Stanford, CA.

Griffin, R. J., S. Dunwoody, and K. Neuwirth. 1999. Proposed model of the relationship of risk information seeking and processing to the development of preventive behaviors. Environ. Res. Sect. A 80:S230-S245.

Huijps, K., T. J. G. M. Lam, and H. Hogeveen. 2008. Costs of mastitis: Facts and perception. J. Dairy Res. 75:113-120.

Hulsen, J., and T. J. G. M. Lam. 2008. Udder Health. A practical guide to first-rate udder health. Roodbont Publishers, Zutphen, the Netherlands.

Jansen, J., D. Kuiper, R. J. Renes, and C. Leeuwis. 2004. Baseline survey mastitis: Knowledge, attitude and behavior (in Dutch). Communication and Innovation Studies, Wageningen University, Wageningen, the Netherlands.

Jansen, J., B. H. P. Van den Borne, R. J. Renes, G. Van Schaik, T. J. G. M. Lam, and C. Leeuwis. 2009. Explaining mastitis incidence in Dutch dairy farming: The influence of farmers' attitudes and behavior. Prev. Vet. Med. 92:210-223.

Janz, N. K, and M. H. Becker. 1984. The health belief model: A decade later. Health Educ. Q. 11:1-47.

Lam, T. J. G. M., J. Jansen, B. Van den Borne, and J. Van Veersen. 2007. A structural approach of udder health improvement via private practitioners: ups and downs. Pages 142-151 in Natl. 
Mastitis Counc. Ann. Mtg. Proc., San Antonio, TX. Natl. Mastitis Counc., Inc., Madison, WI.

LeBlanc, S. J., K. D. Lissemore, D. F. Kelton, T. F. Duffield, and K. E. Leslie. 2006. Major advances in disease prevention in dairy cattle. J. Dairy Sci. 89:1267-1279.

Leeuwis, C. 2004. Communication for Rural Innovation. Rethinking Agricultural Extension. 3rd ed. Blackwell Science Ltd., Oxford, UK

Likert, R. 1932. A technique for the measurement of attitudes. Arch. Psychol. 140:1-55.

Mee, J. F. 2007. The role of the veterinarian in bovine fertility management on modern dairy farms. Theriogenology 68:S257S265.

Petty, R. E., and J. T. Cacioppo. 1986. The elaboration likelihood model of persuasion. Pages 123-205 in Advances in Experimental Social Psychology. L. Berkowitz, ed. Academic Press, New York, NY.

Petty, R. E., and D. T. Wegener. 1999. The elaboration likelihood model: Current status and controversies. Pages 41-72 in DualProcess Theories in Social Psychology. S. Chaiken and Y. Trope, ed. Guilford Press, New York, NY.

Rodrigues, A. C. O., D. Z. Caraviello, and P. L. Ruegg. 2005. Management of Wisconsin dairy herds enrolled in milk quality teams. J. Dairy Sci. 88:2660-2671.

Rogers, R. W. 1983. Cognitive and physiological processes in fear appeals and attitude change: A revised theory of protection motivation. Pages 153-176 in Social Psychology: A Source Book. J. T. Cacioppo, and R. E. Petty, ed. Guilford Press, New York, NY.

Sheeran, P. 2002. Intention-behavior relations: A conceptual and empirical review. Eur. Rev. Soc. Psychol. 12:1-36.

Snyder, L. B., and M. A. Hamilton. 2002. A meta-analysis of U.S health campaign effects on behavior: Emphasize enforcement, exposure and new information, and beware the secular trend Pages 357-383 in Public Health Communication: Evidence for Behavior Change. R. Hornik, ed. Lawrence Earlbaum Associates, Hillsdale, MI.

Snyder, L. B., M. A. Hamilton, E. W. Mitchell, J. Kiwanuka-Tondo, F. Fleming-Milici, and D. Proctor. 2004. A meta-analysis of the effect of mediated health communication campaigns on behavior change in the United States. J. Health Commun. 9:71-96.

SPSS Inc. 2007. SPSS version 15.0 for Windows, SPSS Inc., Chicago IL.

Valeeva, N. I., T. J. G. M. Lam, and H. Hogeveen. 2007. Motivation of dairy farmers to improve mastitis management. J. Dairy Sci. 90:4466-4477.

Webb, T. L., and P. Sheeran. 2006. Does changing behavioral intentions engender behaviour change? A meta-analysis of the experimental evidence. Psychol. Bull. 132:249-268. 